\title{
Equidade, justiça distributiva e a repar- tição dos royalties do pré-sal: uma releitura de J. Rawls
}

\section{Fairness, distributive justice and the appor- tionment of the pre-salt royalties: a new analysis from Rawls' theory}

\author{
Natércia Sampaio Siqueira ${ }^{1}$ \\ Eduardo Daniel Lazarte Moron ${ }^{2}$
}

\begin{abstract}
Resumo: Este artigo revisita a teoria da justiça de John Rawls para abordar o debate judicial sobre as regras de distribuição dos royalties e participações especiais devidos pela exploração de petróleo no Pré-Sal (pela Lei federal n. $\left.{ }^{\circ} 12.734 / 2012\right)$, enfatizando a relevância do critério da equidade para a análise desse caso que se encontra sob julgamento no Supremo Tribunal Federal. A partir do exame dos argumentos apresentados até o momento pelos Ministros do STF na Ação Direta de Inconstitucionalidade 4.917, avalia-se o quanto se aproximam ou se distanciam das premissas básicas
\end{abstract}

1 Mestrado em Direito Tributário pela Universidade Federal de Minas Gerais (2002) e Doutorado em Direito Constitucional pela Universidade de Fortaleza (2011). É Pós-doutoranda em Direito econômico na Faculdade de Direito da Universidade de Lisboa, Professora do curso de Pós-graduação (mestrado e doutorado) em direito Constitucional da Universidade de Fortaleza e membro do CELA. E-mail: naterciasiqueira@yahoo.com.br

2 Mestre em direito ambiental e doutorando em direito constitucional pela Universidade de Fortaleza. E-mail: lazla8@hotmail.com 
fixadas por Rawls para uma justa distribuição em um esquema cooperativo. Embora a teoria da justiça de Rawls tenha sido pensada para uma sociedade de pessoas, a hipótese é que, na sua essência, poderia ser válida também para a análise de um esquema cooperativo como a federação, em que os entes federativos estaduais seriam equivalentes às pessoas. São pensados desde logo três modelos distributivos possíveis: (I) um em que os Estados da federação que são potencialmente afetados (em alguma medida) pela exploração devem receber com exclusividade e de forma igual entre si os royalties; (II) um em que os Estados que são potencialmente mais afetados pela exploração devem receber uma parte maior dos royalties, mas os demais Estados também devem receber uma parte, ainda que menor, pois fazem todos parte de uma federação; e (III) um em que os Estados todos, independente do quanto sejam, ou não, potencialmente afetados, devem receber partes iguais dos ganhos da exploração do Pré-Sal, de vez que os ganhos (receitas) da federação devem aproveitar a todos. Interessado em saber quanto cabe a quem, e como a noção de equidade pode oferecer a resposta mais apropriada, este artigo, a partir do estudo de caso, utiliza-se de um método quali-quantitativo. Conclui-se que o modelo distributivo mais compatível com os princípios de justiça defendidos por Rawls, incluindo o princípio da diferença, seria aquele em que os Estados que são potencialmente mais afetados pela exploração devem receber uma parte maior dos royalties.

Palavras-chave: Royalties do Pré-Sal; Justiça como equidade; John Rawls; Supremo Tribunal Federal.

Abstract: This paper revisits John Rawls's theory of justice to address the judicial debate on the rules for distribution of royalties and special participations due 
to oil exploration in the Pre-Salt (Federal Law 12.734 / 2012), emphasizing the relevance of the Criterion of fairness for the analysis of this case that is under judgment in the Federal Supreme Court. From the examination of the arguments presented so far by the STF Ministers in Direct Action of Unconstitutionality 4,917, it is assessed how close or distant they are to the basic premises set by Rawls for a fair distribution in a cooperative scheme. Although Rawls's theory of justice was intended for a society of people, the hypothesis is that, in essence, it could also be valid for the analysis of a cooperative scheme such as federation, where state federative entities would be equivalent to people . Three possible distributive models are thought of: (i) one in which states of the federation that are potentially affected (to some extent) by the holding must receive exclusive and equal amounts of royalties from each other; (II) one in which states that are potentially most affected by exploitation should receive a larger share of royalties, but other states should also receive a portion, albeit a minor one, as they are all part of a federation; And (iii) one in which all States, regardless of whether or not they are potentially affected, shall receive equal shares of the Earnings from the pre-salt exploitation, since the federation's earnings (proceeds) shall enjoy all. Interested in knowing how much it is up to who, and how the notion of fairness can offer the most appropriate answer, this article, from the case study, uses a qualitative-quantitative method. It is concluded that the distributive model most compatible with the principles of justice advocated by Rawls, including the principle of difference, would be the one in which the states that are potentially more affected by the exploitation must receive a greater part of the royalties.

Keywords: Royalties Pre-Salt; Justice as fairness; John Rawls; Brazilian Supreme Court. 


\section{Introdução}

Neste artigo, tomando como parâmetro os critérios de justiça distributiva oferecidos pela teoria de John Rawls discute-se qual seria a decisão mais "justa" a ser tomada pelo STF na ADI n ${ }^{\circ} 4917$, que trata da distribuição dos royalties do pré-sal em relação aos entes federativos. A discussão põe em questão, mais especificamente, se a concepção de justiça como equidade de Rawls, embora idealizada para avaliar um "pacto social" (sociedades de pessoas), poderia servir para avaliar um pacto federativo.

Se o filósofo acreditou que os princípios cardeais de sua concepção de justiça poderiam ser estendidos para a sociedade dos povos, entende-se que não haveria óbice para sua aplicação em um esquema cooperativo, a exemplo da federação. Esta poderia, inclusive, ser considerada uma derivação da ideia kantiana de foedus pacificum.

Muito embora se reconheça que o tema das regras de distribuição dos royalties e participações especiais devidos pela exploração de petróleo no pré-sal tenha relevância no cenário internacional a partir da perspectiva energética e ambiental, não é foco deste trabalho analisar tais aspectos.

Nessa esteira, o artigo, após a descrição do caso, destaca os possíveis modelos distributivos possíveis: (I) um em que os Estados da federação que são potencialmente afetados (em alguma medida) pela exploração devem receber com exclusividade e de forma igual entre si os royalties; (II) um em que os Estados que são potencialmente mais afetados pela exploração devem receber uma parte maior dos royalties, mas os demais Estados também devem receber a sua parte, ainda que menor, pois todos integram a federação; e (III) um em que os Estados todos, independente do quanto sejam, ou não, potencialmente afetados, devem receber partes iguais dos ganhos da exploração do Pré-Sal, de vez que os ganhos 
(receitas) da federação devem aproveitar a todos.

$\mathrm{O}$ artigo se serve amplamente dos argumentos apresentados por Rawls no seu texto "Uma teoria da justiça" para analisar qual o método de distribuição dos Royalties que se mostra adequado à axiologia elementar da democracia, incluindo o princípio da diferença e a justa oportunidade, sobretudo para mostrar que a abordagem política da concepção da justiça distributiva por ele desenvolvida pode fornecer orientação segura para discussões sobre a justa distribuição dos ônus e bônus de um esquema cooperativo qualquer.

A hipótese ao final confirmada é de que o modelo (II) seria o mais condizente com os princípios rawlsianos da justiça, uma vez que abraça tanto o aspecto da responsabilidade como da distribuição. Ainda que se adote uma perspectiva institucional da posição original, adverte-se que em última análise os entes federados são instituições que refletem o dever de se assegurar a todas as pessoas de um determinado país, justas oportunidades de desenvolvimento e de participação.

\section{Os royalties do Pré-Sal}

Em termos técnicos, a expressão denominada de "Pré-sal" configura um intervalo de rochas localizadas antes da camada de sal. Conceitualmente, o termo "Pré-sal" que permeia a mídia e até textos técnicos aproxima-se de uma definição de caráter geológico temporal, que significa o intervalo de rochas que foi depositado antes de camadas de sal. Neste conceito, os reservatórios que lá ocorram devem ser considerados simplesmente mais velhos que uma camada de sal autóctone, em discussão. Tem, portanto, caráter geocronológico ${ }^{3}$.

3 PAPATERRA, 2010, p. 40. 
O primeiro poço exploratório a ultrapassar a espessa camada de sal, em águas ultraprofundas, na bacia de Santos, foi o poço pioneiro 1-BRSA-329D-RJS, localizado no bloco exploratório BM-S-10 (prospecto Parati), licitado na Segunda Rodado de Licitações da ANP, em 2000. Esses reservatórios começaram a ser explorados pela Petrobrás com a inauguração da plataforma P-50, em 2006, ocasião em que se celebrou a possível autossuficiência brasileira em petróleo ${ }^{4}$.

Em abril de 2006, com a inauguração da Plataforma P-50 na Bacia de Campos, o Brasil alcançou a tão desejada autossuficiência em petróleo. A partir daí o objetivo passou a ser a manutenção dessa autossuficiência, o que requeria a descoberta de novas reservas de petróleo. Os investimentos efetuados na Bacia de Santos na última década, inicialmente pela Petrobras e posteriormente pelas empresas a ela consorciadas, resultaram na descoberta das ocorrências do pré-sal, as quais ainda se encontram em avaliação pelas companhias petrolíferas $^{5}$. Após a inauguração da Plataforma P-50, na Bacia de Campos, com vistas a ampliar as possibilidades de autossuficiência em petróleo, o Brasil continuou buscando mais blocos exploratórios, culminando com a descoberta das reservas do pré-sal.

A Petrobras definiu as rochas do pré-sal como reservatórios situados sobre extensa camada de sal na região costa-afora entre os estados do Espírito Santo e Santa Catarina, numa faixa com cerca de $800 \mathrm{~km}$ de comprimento por 200 $\mathrm{km}$ de largura ${ }^{6}$.

No final de 2007, foi anunciada a descoberta de ocorrências de hidrocarbonetos em águas ultraprofundas da Bacia de Santos, ainda no Pré-sal, que poderia colocar o Brasil na

4 PAPATERRA, 2010, p. 40.

5 RICCOMINI, SANT'ANNA e TASSINARI, 2012, p. 41.

6 RICCOMINI, SANT'ANNA e TASSINARI, 2012, p. 41. 
lista dos principais países produtores de petróleo e gás do mundo ${ }^{7}$.

A descoberta de grandes volumes de hidrocarbonetos no pré-sal abriu novas perspectivas para a economia brasileira. Testes preliminares em áreas do pré-sal forneceram previsões de volumes recuperáveis de até 16 bilhões de barris de óleo equivalente, comparáveis às atuais reservas brasileiras de petróleo e gás. As estimativas das reservas indicam potencial de 70 a 100 bilhões de barris de óleo equivalente ${ }^{8}$.

Nesse novo cenário de descoberta das reservas do Pré-sal promoveu-se a alteração legislativa da Lei federal $\mathrm{n}^{\mathrm{o}} 9.478 / 1997$, por meio da Lei federal $\mathrm{n}^{\circ} 12.734 / 2012$, com a finalidade de estabelecer novas regras de distribuição dos royalties e participações especiais devidos pela exploração do petróleo.

Em síntese, a nova lei estabelece uma forma própria de rateio das participações nos ganhos oriundos da exploração, ao colocar no centro das preocupações não os entes produtores como determina a Constituição, e sim os Estados federativos todos, incluindo os que não sofrem os impactos e os riscos associados à exploração de petróleo.

Em março de 2013, foi ajuizada a ADI 4917 pelo Governador do Estado do Rio de Janeiro, com pedido de medida cautelar, questionando a constitucionalidade das novas regras do regime de distribuição dos royalties e participações especiais devidos pela exploração do petróleo, introduzidas pela Lei 12.734/2012. A tese central da ADI é de que o pagamento de royalties e participações especiais insere-se no pacto federativo originário da Constituição de 1988, a mostrar-se como contrapartida ao regime diferenciado do ICMS incidente sobre o petróleo, bem como envolve, por

7 RICCOMINI, SANT'ANNA e TASSINARI, 2012, p. 41.

8 RICCOMINI, SANT'ANNA e TASSINARI, 2012, p. 41. 
imperativo do art. 20, $\S 1^{\circ}$, uma compensação pelos ônus ambientais e de demanda por serviços públicos gerados pela exploração desse recurso natural.

A nova forma de distribuição dos royalties, segundo alegação do Estado do Rio de Janeiro, provoca uma ruptura do próprio equilíbrio federativo, pois os Estados não produtores passaram a se beneficiar da arrecadação de ICMS e de uma inusitada compensação por prejuízos que nunca tiveram.

Na presente ação, o autor alegou a violação ao princípio federativo ao prever novas regras nos critérios de fixação de valores a serem pagos aos Estados e Municípios, em cujos territórios haja exploração de petróleo ou cuja área marítima seja confrontante com o território da pessoa política.

O disposto no $\S 1^{\circ}$ do art. 20 da Constituição brasileira garantiu aos Estados, Distrito Federal e Municípios à participação no resultado da exploração de petróleo ou gás natural, de recursos hídricos para fins de geração de energia elétrica e de outros recursos minerais no respectivo território, plataforma continental, mar territorial ou zona econômica exclusiva, ou compensação financeira por essa exploração. Por se tratar de norma de eficácia limitada a sua aplicabilidade dependeu de posterior regulamentação no plano infraconstitucional, por meio da Lei n. ${ }^{09.478 / 1997}$ alterada pela Lei n. ${ }^{\circ}$ 12.734/2012.

Assim, o Estado e o Município, em cujo território se tenha exploração de petróleo ou de gás natural ou que seja confrontante com área marítima na qual se dê referida atividade, fariam jus, em tese, ao direito previsto na norma constitucional. O Estado do Rio de Janeiro fundamenta a sua pretensão nesse dispositivo constitucional, quando alega a existência de direito público subjetivo. Importa ressaltar que a narrativa fática trazida pelos Estados e Municípios para 
se qualificarem como produtores resulta da localização das instalações industriais de processamento, armazenamento e da logística para o escoamento do petróleo e gás natural. Outro aspecto assinalado são as consequências sociais e econômicas da produção ou exploração do petróleo a que estão sujeitos os entes produtores.

Nessa ótica, o autor da ADI ressalta que o direito das entidades federadas, Estados e Municípios deve-se à sua condição territorial e aos ônus que têm de suportar advindos dessa exploração. Daí que o dispositivo constitucional citado lhes garante a participação exclusiva ou no mínimo superior no resultado, como forma de compensação pela exploração de petróleo.

A ADI tem como pressuposto o fato de Estados e Municípios não dotados dos resultados da exploração de petróleo e de gás natural passarem a receber recursos que, em contrapartida, seriam retirados do que se tem como direito dos outros Estados e Municípios, em afronta ao que dispõe o §1. ${ }^{\circ}$ do art. 20 da Constituição.

Diante de referida argumentação, a Ministra Cármen Lúcia deferiu medida cautelar na ADI 4917 para suspender os efeitos dos dispositivos da Lei federal n. ${ }^{\circ} 9.478 / 97$ que regulam a nova forma de distribuição dos royalties do pré-sal. Em sua fundamentação a Ministra Relatora destacou que a questão tem a seriedade própria dos grandes temas federativos e que os efeitos imediatos das novas regras advindas da referida Lei colocariam em risco o prosseguimento dos serviços públicos essenciais estaduais e municipais.

Ao apreciar a medida cautelar, a Ministra Cármen Lucia vislumbrou que a alteração legislativa promovida ao aquinhoar Estados e Municípios não ajustados nas condições territoriais constitucionalmente descritas, com participação nos resultados da exploração de petróleo e gás natural ou 
com valores compensatórios, mostra-se dissonante da norma constitucional apontada como paradigma. Asseverou, ainda, que o enfraquecimento dos direitos de algumas entidades federadas não fortalece a federação, ao contrário, acaba comprometendo-a em sua totalidade.

Em sua decisão, a Relatora também se valeu do princípio da segurança jurídica para deferir a cautelar, como sendo um dos fundamentos da ideia de justiça, pois na sua concepção a finalidade e concretização do direito é a busca da justiça: "Esses institutos são desdobramentos ou especificações do princípio da segurança jurídica, um dos esteios da ideia de Justiça, cuja concretização é buscada pelo direito. $\mathrm{O}$ direito (é ordem normativa) em busca da Justiça (sua finalidade) para tanto propiciando segurança (que é a força do direito para conforto de todas as pessoas)" ${ }^{\prime \prime}$.

Esse trecho do voto implica um reducionismo da finalidade do direito à busca da justiça, o que não se coaduna com a dupla finalidade contemporânea do direito que seria a pacificação social e a prevenção de conflitos. Para melhor fundamentar a afirmação superior, se irá trabalhar a teoria da Justiça de Rawls.

\section{O Porquê de Rawls}

Mas antes de se entrar, especificamente, em Rawls, duas questões metodológicas devem ser abordadas e respondidas: a) a utilidade de aplicar-se uma teoria de justiça para tratar do problema em debate e b) o porquê da escolha pela Teoria da Justiça de Rawls, uma vez que é autor estrangeiro que se

9 BRASIL. Supremo Tribunal Federal. Medida Cautelar na Adi ${ }^{0}$ 4917. Relator: Ministra Carmen Lúcia. Brasília, DF, 18 de março de 2013. Diário de Justiça. Brasília, 18 mar. 2013. Disponível em: $<$ http://www.stf.jus.br/arquivo/cms/noticiaNoticiaStf/anexo/ adi4917liminar. pdf>. Acesso em: 10 jun. 2017. 
propõe a teorizar a democracia no contexto de um Estado de história diferente da brasileira.

Iniciando-se pelo primeiro questionamento, importa considerar aspectos importantes da teoria da Justiça: ela fornece, de maneira racional e crítica, o elemento axiológico que serve de integração ao direito ${ }^{10}$. Referida função se torna tão e mais relevante quando se considera o direito como uma prática interpretativa e não semântica: a construção de uma interpretação séria deve seguir pelo esforço da coerência, cujo elemento axiológico integrador revela-se indispensável $^{11}$. A prática jurídica não se realiza pela demonstração da ocorrência de um fato ${ }^{12}$, ainda que semântico, mas pela razoabilidade na exposição das razões coerentemente articuladas: "moral reasoning is interpretive ${ }^{13 "}$, e um argumento moral interpretativo é tanto melhor do que outro à medida que a interpretação se mostra coerente: "the truth of any true moral judment consists in the truth of na indefinite number of the moral judgement. ${ }^{14 \prime}$

Referida perspectiva de como se dá o direito, por sua vez, permite superar casuísmos repletos de subjetividade e arbitrariedade que se tem servido da ponderação de princípios para apresentar-se com roupagem científica. As urgências fáticas, que justificariam a preterição de um princípio por outro, em não raros os casos são apuradas por preconceitos, ao invés de objeto de análise imparcial. Aqui, entretanto, repita-se: referida metodologia, além de eivada de arbitrariedades que colonizam o direito ao interesse de grupos específicos da sociedade - na compreensão desta

10 SIQUEIRA e SIQUEIRA, 2015, p. 241.

11 DWORKIN, 1999, p. 264.

12 DWORKIN, 2011, p. 115.

13 DWORKIN, 2011, p. 127.

14 DWORKIN, 2011, p. 117. 
realidade, ajuda a abordagem da public choice ${ }^{15}$, falha em lhe conferir um caráter sistémico, o que termina por minar a sua seriedade enquanto empresa interpretativa.

E já aqui, adentra-se no segundo ponto: o elemento axiológico que informa e integra a prática interpretativa é passível de ser compartilhado entre diferentes países, de diferentes histórias, ao se trabalhar com a hipótese de que a democracia possui conteúdo substancial. E é deste pressuposto Rawlsiniano que se parte: as sociedades democráticas possuem uma específica axiologia que informa e condiciona os seus elementos constitutivos, tais quais o direito, a economia, a política. Na teoria da Justiça de Rawls - o que está em conformidade com o pensamento político norte americano que se difundiu, culturalmente, por entre os países democráticos do ocidente - o elemento axiológico característico das sociedades democráticas é a equanimidade, a significar um pacto cooperativo equitativo, e não hierárquico, entre pessoas igualmente livres.

Referido conteúdo democrático é o elemento integrador do direito em uma democracia. Por óbvio que a realidade, histórica, cultural e normativa do Brasil demandará aplicações próprias desse elemento que poderão ser distintas das realizadas em outros países. Mas a ideia da qual se parte é a mesma, razão pela qual não há óbice a se respaldar referida análise em autores estrangeiros; no caso, John Rawls.

\subsection{A teoria da Justiça de Rawls}

A escolha específica por Rawls justifica-se à medida que se expõe a sua teoria e que se trazem os seus próprios argumentos para fundamentar a equanimidade como ele-

15 ARAÚJO, 2007, p. 89. 
mento axiológico integrador da democracia.

A teoria da justiça como equidade, conforme trabalhada pelo autor estadunidense, se pretende reconhecida como uma concepção da justiça adstrita ao domínio da política, posto que seu campo de aplicação é a razão publica. Ainda esclarece que o senso de justiça, caracterizado pela razoabilidade que, segundo o mesmo, é uma das duas faculdades morais elementares à pessoa numa democracia, implica a capacidade de compreender, aplicar, observar e se conformar a uma concepção pública da justiça que caracteriza os termos de uma cooperação equitativa. Ou seja, a Teoria da justiça de Rawls é uma concepção política e não moral, isto é, não se revela como a axiologia a informar visões de mundo dos indivíduos - razão privada; antes, é o conteúdo da razão pública adequada para inspirar e guiar o debate e as decisões elementares acerca das instituições políticas, sociais e econômicas ${ }^{16}$.

Melhor explicando: a equanimidade implica a consideração de que as diferentes visões de mundo são igualmente boas, de maneira que uma visão particular não pode servir como elemento axiológico a informar a estrutura básica da sociedade ${ }^{17}$ sob o risco de desestabilizar a cooperação equitativa entre iguais. Por conseguinte, a razão pública deve mostrar-se de ser passível de ser compartilhada por pessoas de diferentes religiões, posições políticas e filosofias de vida, num acordo entrecruzado. Referida axiologia, por sua vez, teria por contexto elementar a cooperação equitativa entre pessoas livres e iguais - o que, é verdade, já está a lhe fornecer conteúdo material - e se especificaria nos dois princípios de justiça de Rawls: igualdade de liberdades básicas ( $1^{\circ}$ Princípio de Justiça de Rawls) e Justa oportunidade + o princípio

16 RAWLS, 2000, p. 216.

17 RAWLS, 1999, p. 459-461. 
da diferença ( $2^{\circ}$ Princípio de Justiça de Rawls $)^{18}$.

\subsection{Os princípios de Rawls}

Conforme já mencionado, a cultura pública própria de uma democracia, ao concebê-la como cooperação equitativa entre pessoas livres e iguais, leva aos dois princípios de justiça com o propósito específico de efetivar os valores da igualdade e liberdade.

Segundo John Rawls os princípios seriam (1) Cada pessoa tem um direito igual a um sistema plenamente adequado de liberdades básicas iguais para todos, que seja compatível com um mesmo sistema de liberdades para todos (2) As desigualdades sociais e econômicas devem satisfazer a duas condições: (a) elas devem primeiro ser ligadas a funções e a posições abertas a todos, em condições de justa (fair) igualdade de oportunidades e (b) devem proporcionar o maior benefício aos membros mais desfavorecidos da sociedade. ${ }^{19}$

Rawls ${ }^{20}$ propõe que esses princípios estariam de acordo com nossas conviçções mais sólidas e bem ponderadas, correspondendo àqueles que seriam escolhidos por indivíduos puramente racionais (cegos por um "véu de ignorância" para as nuances conjunturais) em uma situação hipotética que simulasse um contrato social (a "posição original"). Melhor explicando: ele chega ao conteúdo dos princípios que informam a razão pública, mediante procedimento hipotético no qual busca a resposta de qual axiologia elementar à sociedade seria a escolhida entre "pessoas" - caracterizadas pela faculdade a) de "racionalmente" elaborar, revisar e vivenciar um

\footnotetext{
18 RAWLS, 2000, p. 144.

19 RAWLS, 2000, p. 144-145.

20 RAWLS, 2000, p.209.
} 
plano ou modelo de vida e b) de "razoavelmente" adotar e aplicar princípios de justiça condicionantes aos seus projetos particulares - "livres" - no exercício da racionalidade - e "iguais" - sujeitas às restrições recíprocas da racionalidade pela razoabilidade - cuja ciência das suas características e condicionamentos reais - biológicas, culturais, familiares, climáticas - estivesse obliterada pelo "véu da ignorância". A igualdade de liberdades básicas, a justa oportunidade e $o$ princípio da diferença seriam a resposta, uma vez que essas "pessoas" "livres", "iguais" e "ignorantes" quanto aos seus contingenciamentos fáticos teriam o interesse de escolher os princípios que lhes possibilitassem as melhores condições para o exercício da racionalidade.

No contexto do que acima se colocou, passa-se a compreender o princípio da diferença. Na posição original os pactuantes não sabem se pertencem ao grupo dos melhores ou piores posicionados socialmente. Diante desta última hipótese, e sabedores da importância da racionalidade à dignidade da pessoa, os representantes da sociedade, que se reconhecessem e todos os outros como pessoas livres e racionais, optariam pelo princípio que possibilitaria as melhores condições de vida para quem estivesse na classe dos piores situados sócio, cultural e economicamente: os princípios de justiça não permitem a melhor situação possível a todos, mas às minorias e aos desafortunados ${ }^{21}$. Ainda para melhor se elucidar a opção pelo Princípio da Diferença, é importante que se ressalte o seu pressuposto: os piores situados ainda estariam em melhor situação numa sociedade de desigualdade do que se a riqueza fosse igualmente distribuída. Isto, porque a desigualdade de riqueza não apenas é consequência da igualdade de liberdades básicas, como porque ela possibilita uma melhor eficiência à economia. De maneira que,

21 KYMLICKA, 2006, p. 84. 
se sobre a desigualdade se aplicar o princípio da Diferença, as suas mais graves consequências idiossincráticas estariam superadas mediante a institucionalização do repasse aos menos favorecidos dos melhoramentos obtidos pelos mais favorecidos.

Muitas críticas se fizeram, entretanto, ao princípio da diferença. Entre elas, talvez a mais poderosa, é a de que referido princípio estaria a privilegiar a irresponsabilidade. Mas Rawls responde de várias formas a esse argumento. De primeiro, quando caracteriza a sociedade como cooperação. Ao falar do surfista de Malibu, diz que não haveria obrigação por parte do Estado de assegurar uma parte na distribuição social para uma pessoa que é um ocioso convicto. De segundo, quando adverte sobre o amálgama entre responsabilidade e inexorabilidade dos condicionamentos fáticos: mesmo o esforço e o propósito de ser bem sucedido estariam a depender de condições familiares salutares ${ }^{22}$.

Assim, diante do conteúdo ao princípio da diferença, de suas críticas e dos argumentos dos quais lança mão Rawls para judificá-los, levanta-se o questionamento de se ele poderia ser aplicado ao ambiente da federação. Isto, porque o caráter de cooperação defendido por Rawls poderia ser deduzido do pacto federativo, sendo o federalismo necessariamente cooperativo. Com base nisso, poder-se-ia afirmar que todos os entes da federação devem ter justas oportunidades para desenvolverem as suas funções constitucionais e qualquer política de distribuição dos ganhos deveria aproveitar em alguma medida a todos.

22 RAWLS, 1971, p. 74. 


\section{O justo rateio e o princípio da diferença}

Segundo Rawls, uma sociedade de pessoas em que todos ganham igualmente, embora se dediquem diferentemente, não seria justa, do mesmo modo que uma sociedade em que cada indivíduo ganha conforme a sua dedicação e outros não se beneficiem dessa condição, também não se afiguraria justa. Rawls mostra-se sensível tanto ao caráter da responsabilidade como da cooperação: a desigualdade social e econômica é justa desde que se assegurem oportunidades equitativas de preenchimento dos cargos e funções de responsabilidade abertos a todos e que se possibilitem aos menos favorecidos os benefícios decorrentes da diferença de riqueza e prestigio social. A distribuição é, desta forma, elementar à cooperação sob princípios de justiça que reciprocamente limitem a liberdade.

A propósito disso, na visão de Silva e Ramos ${ }^{23}$, Rawls não cogita a eliminação dessas diferenças e tampouco refuta a possibilidade de os mais favorecidos genética ou socialmente auferirem maiores benefícios decorrentes da cooperação social. Todavia, essa situação, por força do princípio da diferença, não deve ser justificada em razão da posse de talentos naturais ou do pertencimento a uma classe social mais elevada, mas sim da elevação da situação daqueles que são mais desfavorecidos socialmente. Dessa forma, vê-se que Rawls é considerado um liberal-igualitário não porque defenda a igual distribuição de oportunidades, renda e riqueza, mas por permitir que as desigualdades na distribuição dos bens primários só sejam toleradas se resultarem na maior fruição pelos menos favorecidos das suas liberdades básicas.

23 SILVA e RAMOS, 2017, p. 179-180. 
Em texto sobre a aplicabilidade da teoria rawlsoniana de justiça como fundamento para a justificação do direito à saúde, Silva e Ramos ${ }^{24}$ defendem a extensão das ideias de Rawls à saúde, de modo a concebê-la enquanto problema de justiça distributiva. Com efeito, a saúde é um problema dessa ordem na medida em que é resultado e causa das desigualdades sociais. A defesa feita pelos autores serve de inspiração para que a teoria da justiça de Rawls possa ser utilizada em um problema de justiça distributiva que tenha por objeto a distribuição dos royalties do pré-sal entre os entes da federação.

Pois bem, detém-se, em um primeiro lugar, no caráter pessoal da Teoria Rawlsiniana antes de se investir numa abordagem institucional mediante a analogia entre pessoa e os entes federativos. É importante, efetivamente, chamar a atenção para o fato de que a partir de um conceito de pessoa, Rawls atribui conteúdo aos princípios de justiça sobre os quais se devem estruturar os institutos sociais, como a política, a economia, o direito e a família. O dado basilar é a pessoa, caracterizada pela racionalidade e razoabilidade. Talvez, a um primeiro golpe de percepção, a teoria de Rawls, por este caráter pessoal, se mostre inadequada pera ser aplicada na problemática da qual hora se trata. Mas é uma compreensão equivocada.

Isto, porque os entes federados descentralizados, mais especificamente estados e município, principalmente os últimos, são esferas de sociabilização mais sensíveis às individualidades. Em especial, em um País de dimensão continental e de grande diversidade cultural como o Brasil: o homem do sertão da caatinga nordestina é de todo diverso do cosmopolita paulistano, o indígena confinado à imensidão amazônica pouco tem em comum, culturalmente, com

24 SILVA e RAMOS, 2017, p. 186. 
descendentes de poloneses, lituanos e de outras nacionalidades europeias que vieram aportar no sul brasileiro em fuga de conflitos bélicos e perseguições políticas. A natureza e o clima, também têm a sua parcela de responsabilidade na geração de situações específicas, que não se mostram aptas a deliberações centralizadoras e abstratas.

Em termos mais sintéticos: o crescente grau de localidade é diretamente proporcional ao grau de pessoalidade do ente federado, o que é fundamental à noção material de democracia: "democracia é o domínio do cidadão, não do povo, no sentido de Rousseau ${ }^{25}$." Este dado deve ser trabalhado no contexto de que os mecanismos de cooperação entre pessoas livres e iguais são institucionais: uma série de instituições políticas e econômicas direcionadas à realização dos princípios de justiça. Uma dessas instituições é o ente federado: se à União cabem matérias necessariamente estratégicas a todo o território nacional, como as referentes às relações diplomáticas e à defesa da soberania, ao Estados cabem questões regionais e aos municípios as questões locais, como serviço público de transporte, de creche e ensino infantil e fundamental. São instituições que se voltam, em última instância, seja mediata ou imediatamente, à pessoa: aqui, lembra-se uma vez mais, quanto menos central e universal, mais a atuação publica volta-se, direta e imediatamente, ao indivíduo.

De maneira que a operacionalização dos princípios, em especial os da justa oportunidade e o da diferença, passa por políticas distributivas que se estendem por todas as instituições, inclusive pelos entes federados. Ao considerar que a cooperação é entre todas as pessoas de um país, chega-se à conclusão de que as várias instituições devem se mobilizar para garantirem a todas essas pessoas, de um mesmo país,

25 HABERLE, 1997, p. 38. 
justas oportunidades para se desenvolverem. Esta cooperação, em última instância, é entre pessoas e não pode ser obliterada por uma perspectiva institucional: por se ser de um Estado ou município não se estaria dispensado de cooperação para com as pessoas de outro Estado ou Município. As instituições, em última análise, devem espelhar esse dever "pessoal" de se assegurar a todos justas oportunidades e de introduzir todos nos benefícios da geração de riqueza. Não se está a negar que neste cálculo questões referentes à responsabilidade e aos custos de atuação das instituições devem ser levadas em consideração, uma vez que as pessoas são responsáveis e afetadas pelos assuntos estaduais e locais. Mas o aspecto necessariamente distributivo não pode ser olvidado por uma pura relação sinalagmática contingenciada por aspectos fáticos que fogem à responsabilidade - é exemplo, a riqueza natural.

Neste momento, adentra-se na análise eminentemente institucional que se realiza pela analogia entre os entes federados e as pessoas. Em certa medida, Rawls lançou mão desta analogia ao tratar da questão referente à aplicabilidade dos princípios de justiça em esfera internacional, não obstante tenha se referido a direito, sociedade e representantes "dos povos". O fato é que o modelo Rawlsiniano da cooperação equitativa entre pessoas livres e iguais possui elementos pelos quais também se pode pensar uma cooperação equitativa entre partes iguais, ainda que instituições.

Essa relação equitativa entre iguais demandas não apenas condicionamentos formais, no sentido de não se imporem particularidades de um a outro, como materiais, a significar a criação de oportunidades equânimes de desenvolvimento, sem que isso implique assegurar igual nível material de recursos a cada participante. Esta dinâmica, conforme o já ressaltado, abraça a responsabilidade e a dis- 
tribuição. Por consequência, pode-se afirmar: se todos os Estados da federação tivessem direito ao mesmo percentual dos royalties do Pré-sal, embora alguns (ou muitos) não participem do processo de produção e exploração do petróleo, não se teria uma distribuição justa. Do mesmo modo, também não seria justa que a distribuição dos royalties se limitasse aos Estados potencialmente afetados com essa exploração ou diretamente ligados à sua produção.

Ainda sobre o assunto, é interessante utilizar-se da advertência de Rawls de que contingências da natureza são arbitrárias pelo parâmetro do justo. No caso do Pré-Sal, a "dedicação" de cada Estado, até dos Estados produtores, está diretamente ligada à descoberta dos recursos naturais; ora, considerando-se que eles sempre estiveram no fundo do mar e sua descoberta não deixa de ser uma obra do acaso. Não se pode imaginar que os outros Estados que não abrangidos pelas reservas do Pré-Sal não sejam cooperativos. Não se pode atribuir qualquer mérito aos entes federativos pela simples descoberta de petróleo em sua costa marítima, afastando-se, com isso, o argumento da exclusividade em seu favor.

Em outros termos, uma teoria da justiça ao mesmo tempo liberal e igualitária teria como finalidade corrigir essas desigualdades que são fruto do acaso, razão pela qual eles mereceriam algum quinhão nessa justa distribuição, ainda que fosse um quinhão inferior do que o destinado aos Estados e Municípios produtores. Somente a constatação de um "mérito" atribuído aos Estados produtores na descoberta do petróleo ou havendo qualquer impacto ambiental, a distribuição dos royalties não seria orientada pelo princípio da igualdade, correspondendo um maior percentual aos Estados produtores.

A ideia intuitiva fundamental é que a federação integra um sistema equitativo de cooperação entre os Estados, de 
modo que não pode ser excludente nem arbitrariamente discriminatório. Essa ideia acaba destacando aquilo que todos os que estão envolvidos na cooperação procuram atingir, quer sejam indivíduos, família ou até mesmo Estados da federação. As condições de um acordo equitativo calcados nos princípios da justiça seriam dependentes de um compromisso com a redução das desigualdades entre os sujeitos.

Ademais, não se discute na ADI a existência de provas concretas que confirmem qualquer impacto ambiental negativo aos Estados produtores, de maneira que sequer esse argumento seria definitivo para que os Estados produtores tivesse direito a maior na distribuição dos Royalties, quanto mais à exclusividade. Pela ideia da justiça como cooperação equitativa entre partes iguais, não é justificável que a simples existência do petróleo na costa do Estado do Rio de Janeiro ou de qualquer outro estado seja razão suficiente para se lhe atribuir o direito à exclusividade dessa exploração.

A eventual decisão de mérito da ADI no STF pode se deparar com, pelo menos, três cenários: (I) que a distribuição dos royalties seja feita integralmente em favor dos Estados potencialmente afetados ou considerados produtores; (II) que a distribuição dos royalties seja feita em um percentual maior aos Estados produtores e em percentual menor aos demais Estados e municípios, desde que se verifique algum mérito (bônus) ou impacto ambiental (ônus) na descoberta dos royalties em favor ou desfavor dos Estados produtores; e (III) que a distribuição dos royalties seja feita de forma igualitária entres todos os Estados e municípios da federação.

O segundo cenário estabelece que os Estados que são potencialmente mais afetados pela exploração recebam uma parte maior dos royalties, mas os demais Estados também receberiam uma parte, ainda que menor, pois todos integram a federação. Esse cenário intermediário, como aqui defendi- 
do, retrata um sistema de cooperação social equitativa e ao mesmo tempo parece aceitável de um ponto de vista político.

\section{Conclusão}

A partir da análise dos fundamentos mencionados para o deferimento da medida cautelar na ADI 4917, em que a urgência restou demonstrada pela possibilidade ou probabilidade de imediata aplicação das novas regras no cálculo e na entrega dos valores devidos a Estados Federados e Municípios. Deduz-se que o STF levou em consideração a instabilidade jurídica, financeira e política resultantes dos efeitos das normas questionadas, para suspender os efeitos da Lei 12.734/2012.

Percebeu-se que a Corte atribuiu a essa urgência a adjetivação de qualificada, pois a discussão envolvia a eficácia do princípio federativo e as regras do modelo constitucionalmente adotadas no regime de exploração do petróleo, acrescidos dos inegáveis riscos à segurança jurídica, política e financeira dos Estados e Municípios. A concepção de justiça distributiva idealizada por Rawls certamente é um caminho positivo para se imaginar a um resultado possível para o julgamento do caso, apontando para um esquema cooperativo que deva nortear a associação entre entes federativos.

Compreendeu-se que em relação à distribuição dos royalties do petróleo, o modelo distributivo mais compatível com os princípios de justiça defendidos por Rawls, incluindo o princípio da diferença, seria aquele em que os Estados potencialmente mais afetados pela exploração devem receber uma parte maior dos royalties, ainda que os demais Estados também devam receber uma parcela, ainda que menor, pois todos integram o sistema federativo. 


\section{Referências bibliográficas}

BRASIL. Constituição da República Federativa do Brasil. Brasília: Senado Federal, 1988. 292 p.

BRASIL. Supremo Tribunal Federal. Medida Cautelar na Adi $n^{\circ}$ 4917. Relator: Ministra Carmen Lúcia. Brasília, DF, 18 de março de 2013. Diário de Justiça. Brasília, 18 mar. 2013. Disponível em: <http://www.stf.jus.br/arquivo/ cms/noticiaNoticiaStf/anexo/adi4917liminar. pdf $>$. Acesso em: 10 jun. 2017.

ARAÚJO, Fernando.Teoria Econômica do contrato. Coimbra: Almedina, 2007.

DWORKIN, Ronald. Justice for hedhogs. Cambridge: Harvard University press, 2011.

O Império do Direito. Tradução: Jeferson Luiz Camargo. São Paulo: Martins Fontes, 1999.

HÄBERLE, Peter. Hermenêutica constitucional. A sociedade aberta dos intérpretes da constituição: contribuição para a interpretação pluralista e procedimental da constituição. Tradução Gilmar Ferreira Mendes. Porto Alegre: Fabris, 1997.

KYMLICKA, Will. Filosofia política contemporânea. Tradução: Luís Carlos Borges. São Paulo: Martins fontes, 2006.

PAPATERRA, Guilherme Eduardo Zerbinatti. Pré-sal: Conceituação Geológica sobre uma Nova Fronteira Exploratória no Brasil. Dissertação de mestrado. Instituto de Geociências, Universidade Federal do Rio de Janeiro, 2010.

RAWLS, John. A theory of justice. Cambridge: Havard University press, 1971 
.Justiça e democracia. São Paulo: Martins Fontes, 2000

. El liberalismo político. Barcelona: Crítica, 1996.

. Social unity and primary goods. In: FREEMAN, Samuel (org). John Rawls: collect papers. Cambridge: Harvard University Press, 1999, p. 359-387.

. The priority of right and ideas of the good. In: FREEMAN, Samuel (org). John Rawls: collect papers. Cambridge: Harvard University Press, 1999, p. 449-472.

RICCOMINI, Claudio; SANT'ANNA, Lucy Gomes; TASSINARI, Colombo Celso Gaeta. Pré-Sal: Geologia e Exploração. Revista da Usp, São Paulo, n. 95, p.33-42, set. 2012. Trimestral. Disponível em: <http://www.iag.usp. br/ eder/3_idade_2_2014/Revista_USP.pdf>. Acesso em: 14 jul. 2017.

SILVA, Delmo da; RAMOS, Edith; DINIZ, Isadora. O direito à saúde no âmbito da justiça como equidade: limites e possibilidades da justiça social na extensão dos direitos sociais em Rawls. Revista Brasileira de Estudos Políticos, Belo Horizonte, v. 115, p.169-201, 2017. Disponível em: <https:// pos.direito.ufmg.br/rbep/index.php/rbep/article/ view/491/431>. Acesso em: 04 abr. 2019.

SIQUEIRA, Marcelo; SIQUEIRA, Natercia. In: Teoria da Justiça: reflexões contemporâneas. BENÍCIO, Márcio; SIQUEIRA, Natercia (coords). Teoria da justiça: sua relevância para a construção de uma prática jurídica ética e democrática. Rio de Janeiro: Lumen Juris, 2015, p. 233-244. 
Recebido em 21/09/2018.

Aprovado em 31/03/2019.

\section{Natércia Sampaio Siqueira}

E-mail: naterciasiqueira@yahoo.com.br

\section{Eduardo Daniel Lazarte Moron}

E-mail: lazla8@hotmail.com 